\title{
Study and Implementation of a Cost-Effective 3L-Active Rectifier for DC Collection in WECS
}

\author{
Muhammad Luqman ${ }^{1 *}$, Yao Gang ${ }^{1}$, Zhou Lidan ${ }^{1}$, Yang Di ${ }^{1}$, and Anil Lamichhane ${ }^{1}$ \\ ${ }^{1}$ Dept. Electrical Engineering, Shanghai Jiao Tong University, 201100 Minhang, China
}

\begin{abstract}
Power electronic converters are widely used in wind energy conversion system (WECS) applications. Therefore, with the increasing manufacturing capacity of multi-MW wind generators, multilevel converters, or parallel configuration of converters are becoming more attractive solutions towards DC collection from the wind generator. Among the multilevel converters, three-level full-scale neutral point diode clamped (3L-NPC) converter are using extensively for such applications in order to reduce the voltage stress on the semiconductor devices. In this article, a comparative study based on several devices used by NPC, capacitor clamped (CC) as well as Vienna rectifier has been done. Furthermore, their estimated cost comparison and complexity of control switches have been debated. By keeping in view the merits and demerits of these rectifiers, a low cost three-level active rectifier having a smaller number of active switches with a simple control scheme have been implemented. Considering a three-phase electric grid as a generated source, a $2.2 \mathrm{KW}$ low-cost three-level Vienna rectifier is simulated using MATLAB/Simulink. DSP (TMS320F28335) based experimental results ratify the simulated circuit with $\mathrm{THD}<5 \%$.
\end{abstract}

\section{Introduction}

Nowadays, the use of wind energy is increasing with an exponential rate in the electrical field ${ }^{[1]}$. Electrical energy is produced from wind energy with the help of directly connected wind turbine through an appropriate generator along with some power electronics converter. Generator side converters have been a part of the early-stage of the wind energy conversion system. Such converters convert a generated electrical energy into direct current (DC) which can be further used as a grid-connected or standalone HVDC system ${ }^{[2]}$. There are three main sorts of rectifiers, namely: passive, active, and hybrid rectifier, which can convert alternating energy into DC. So, these rectifiers play a vital role in DC collection systems. Passive rectifiers create harmonic, and power factor problem on the input side and hybrid rectifiers also have so many drawbacks as generator side converter mentioned in ${ }^{[3]}$. Therefore they are not reflected as an efficient power conversion option. By keeping in view of power-efficient energy conversion, active rectifiers are more attractive towards generator side converter ${ }^{[8]}$.

Generally, there are three commonly used direct threephase active rectifiers named as; two-level, three-level as well as multi-level rectifiers. Among these three types, two-level full bridge rectifier is the most commonly used for low power applications ${ }^{[10]}$. But this topologydoes not meet the requirement of high-power modern multi-MW wind energy conversion system. In the case of multi-MW wind generator, a parallel configuration of rectifiers or multi-level rectifiers plays a vital role to reduce the voltage and current stress on the semiconductor devices ${ }^{[8]}$.Threelevel rectifiers are well matured and most attractive topology for industry and high power applications.

Back to back diode clamped (BBDC) converter, as shown in figure 1(a), is the most common topology of three-level rectifiers as a generator side rectifier. Additionally, another capacitor clamped three-level active rectifier, as shown in figure 1(b), which has a smaller number of diodes as compared to the diode clamped rectifier. These both types of converters have the ability for bi-directional power flow, which is not inevitable for PMSG based energy conversion system ${ }^{[12]}$. But later on, discussed topology has some demerit ${ }^{[9,13]}$.

- Bulky and large in size

- Un-balanced capacitor voltage problem

- Costlier as compared to diode clamped

In view of aforementioned demerits, cost and number of devices used by diode clamped, capacitor clamped along with selected cost-effective three-level active Vienna rectifier have been studied in a good manner. From all three configurations of Vienna rectifiers, as mentioned in ${ }^{[6]}$, a more efficient topology having six switches, as shown in figure 1(c) has chosen for DC collection in WECS. Such rectifier has the ability of continuous flow of current, costeffective, compact in size, easy to control, and implement ${ }^{[13,14]}$. A detailed study about diode and capacitor clamped rectifiers have been done in section 2. Comparison of numbers of semiconductor devices used by these rectifiers and their estimated cost has been studied in section 3 . Section 4 is about the Vienna rectifier and its control. Simulation and experimental results of Vienna rectifier

\footnotetext{
${ }^{*}$ Corresponding author: Luqman@sjtu.edu.cn
} 
have been discussed in section 5 . The paper close with a section of conclusion.

\section{Active rectifiers}

As two-level active rectifier does not meet the requirement for high power WECS. Therefore, only three-level rectifiers have been chosen for under discussion as a generator side converter. From last few decades, 3L$\mathrm{BBDC}$ converter are most famous as a front end of the generator side converter for energy conversion as well as to decouple the electric grid dynamics.

Additionally,by replacing the clamped diodes with capacitors, a new topology was developed, that is known as capacitor clamped converter (CCC) as shown in figure 1(b). These two types of active rectifiers are using a large number of semiconductor devices, as mentioned in Table 1 , which increase the cost and complexity of the system. To design power-efficient and cost-effective system, the most important thing is to use less number of devices. In the case of DC collection from wind energy, a unidirectional power circuit work well instead of the bidirectional circuit. Therefore, a unidirectional Vienna rectifier was selected to use it as a generator side rectifier in WECS.

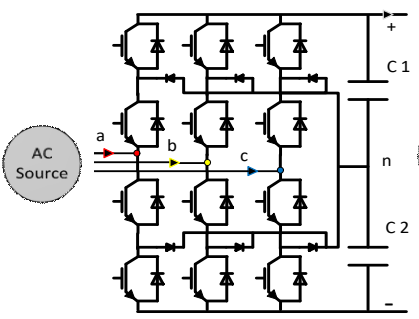

(a)

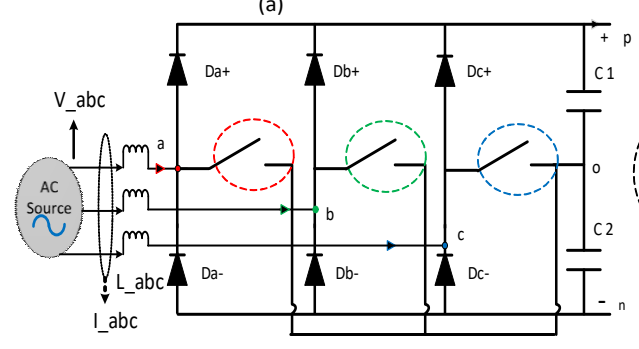

(c)

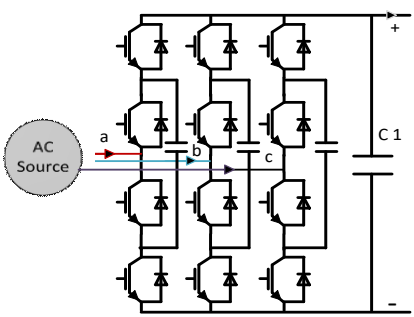

(b)

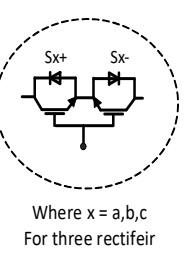
For three rectifeir
Fig. 1. (a) 3-level diode clamped converter, (b) 3-Level capacitor clamped converter, (c) 3-Level Vienna rectifier

\section{Comparative study of $3 \mathrm{~L}$ - active rectifiers}

In this section, a comparison of the number of devices used by pre-defined three-level active rectifiers and their respective total cost have been studied. It can be seen from table.1, that NPC and CCC are using more number of devices as compared to Vienna rectifier. So, Vienna rectifier is the one that is using less number of devices as compared to all other discussed topologies. As the current ripple rejection input filter is common in all kinds of rectifiers. Therefore, during the comparative study, this circuit has been ignored. Cost comparison of three-level active rectifiers has been shown in figure 2 .
Table 1. Devices used by most common 3L-active rectifiers

\begin{tabular}{|c|c|c|c|}
\hline Names & $\begin{array}{l}\text { Diode } \\
\text { Clamped }\end{array}$ & $\begin{array}{l}\text { Capacitor } \\
\text { Clamped }\end{array}$ & $\begin{array}{l}\text { Vienna } \\
\text { Rectifier }\end{array}$ \\
\hline Diodes & 18 & 12 & 12 \\
\hline Capacitors & 2 & 3 & 2 \\
\hline IGBTs & 12 & 12 & 6 \\
\hline IGBTs Drivers & 12 & 12 & 6 \\
\hline $\begin{array}{c}\text { Total \# of } \\
\text { Devices }\end{array}$ & 44 & 39 & 26 \\
\hline
\end{tabular}

The part number and respective cost of fundamental devices used by three phases 3-level discussed circuits have been written in table. 2, while their power handling capabilities have mentioned in ${ }^{[4,5,7]}$.

Table 2. Cost of devices for comparison

\begin{tabular}{|c|c|c|}
\hline Part & Part number & Unit price (\$) \\
\hline IGBT & IKW50N65H5 & 3.52 \\
\hline Diode & APT60DQ120BG & 3.3 \\
\hline Driver & TLP250 & 3.48 \\
\hline Capacitor & ESMR451VSN821MA50S & 11.5 \\
\hline
\end{tabular}

By keeping in view the data mentioned in table 1 and 2, comparison of calculated estimate percentage cost of each discussed three-phase rectifiers is shown in figure 2.

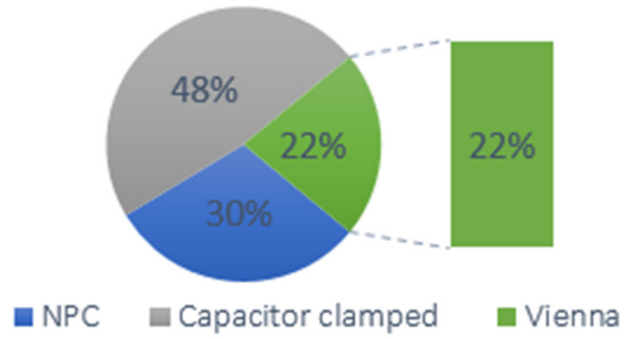

Fig. 2. Estimated percentage cost comparison

\section{Vienna rectifier}

As discussed in the previous section three-level Vienna rectifier (VR) requires a lower number of devices which are more responsive for making it cost-effective, powerefficient and high-power density. It provides low resistance during turn-on of the switch, which leads it towards less voltage stress on the devices ${ }^{[11]}$. Because of the three-level of VR, it can perform higher energy conversion. For three-phase Vienna rectifier all the individual outputs of single-phase rectifiers are added together using two common capacitors $\mathrm{C} 1$ and $\mathrm{C} 2$. The power circuit of three-phase Vienna rectifiers is shown in figure 1(c).

The value of the inductive input filter is calculated by using "(1)", [11].

$$
L_{i}=\frac{v_{\text {bus }}}{8^{*} F_{s w}{ }^{*} \Delta I_{\text {ppmax }}}
$$


Where " $L_{i}$ " is the input inductor, $V_{\text {bus }}$ is a dc bus voltage, $F_{s w}$ is the value of switching frequency and $\Delta I_{\text {ppmax }}$ is a maximum permissible ripple current value.

The terminal voltage of the Vienna rectifier with switching state and polarity of input current can be expressed as:

$$
V_{x n}=\frac{V_{D C}}{2} \operatorname{sgn}\left(I_{x n}\right)\left(1-S_{x}\right)
$$

Whereas, for three-phase

$$
\mathrm{x}=\mathrm{a}, \mathrm{b}, \mathrm{c}
$$

The current average control scheme consists of an outer voltage loop, and the inner current loop has been implemented for Vienna rectifier, as shown in figure 3. The output voltage $V_{d c_{\text {rref }}}$ is compared with sum of the two individual capacitor voltages " $V_{c 1}+V_{c 2}$ ". The result of voltage controller ntroller is multiplied with the absolute value of supply voltage to get reference current for inner loop controller. Difference of capacitor voltages also included in outer loop to balance the midpoint voltages. Inductor current follow the reference current in inner loop to make the power factor true. Finally, the current controller generates pulses after compared with triangular signal to drive the switches.

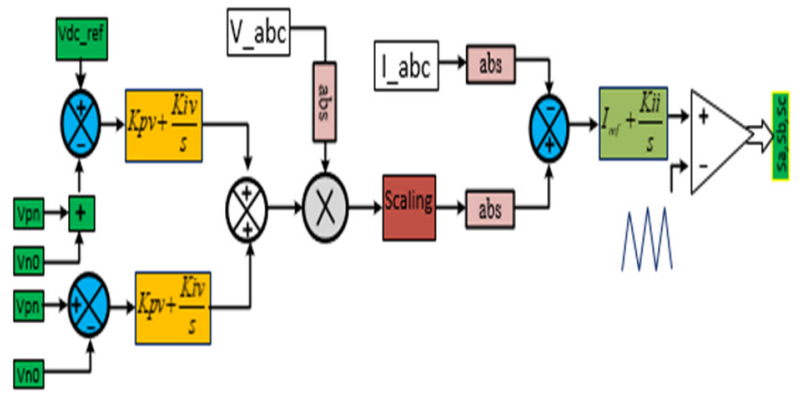

Fig. 3. The control scheme of three-phase Vienna rectifier

\section{Simulation and experimental results}

Simulation and experimental results of Vienna rectifier using current average control method implemented by PI tuning are shown in this section. The parameters used for $2.2 \mathrm{KW}$ rectifier are given in table 3 .

Table 3. Parameters used for simulation and experiment

\begin{tabular}{|c|c|}
\hline Parameters & Values \\
\hline Grid frequency, $\mathrm{f}$ & $50 \mathrm{~Hz}$ \\
\hline Grid supply voltage & $70 \mathrm{Vrms}$ \\
\hline Load resistance, $\mathrm{R}$ & $20 \mathrm{Ohm}$ \\
\hline Switching frequency, Fsw & $15 \mathrm{KHz}$ \\
\hline Input inductor & $220 \mathrm{uH}$ \\
\hline Capacitors C1,C2 & $9020 \mathrm{uF}$ \\
\hline Vdc_ref & 200 Volt \\
\hline
\end{tabular}

\subsection{Simulation results}

The simulation and experimental results are having the same power rating of $2.2 \mathrm{Kw}$ rectifier system. The phase angle between current and line voltage is shown in figure 4(a), which shows the power factor is nearly one that means the power transfer to load is efficient.

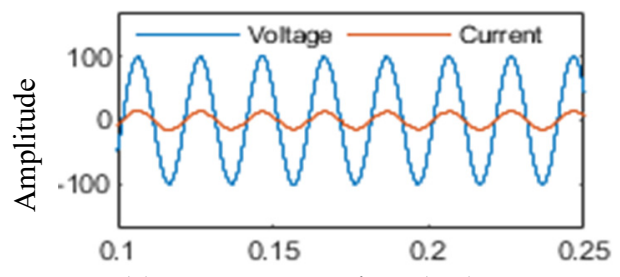

(a) Time (ms)

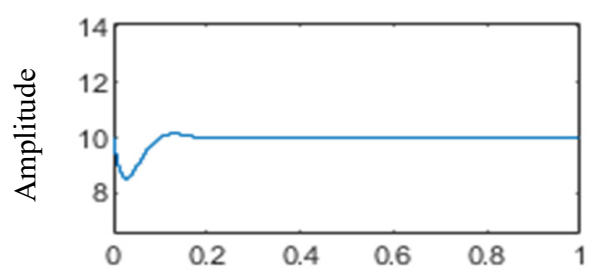

(b) Time (ms)
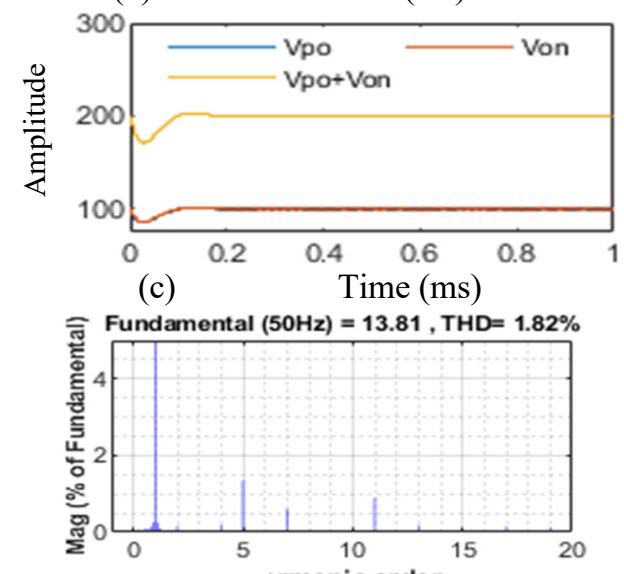

(d)

Fig. 3. (a) Phase angle between voltage and current, (b) load current, (c) DC-link voltages, (d) Total harmonic distortion of input current

\subsection{Experiment results}

The complete setup of directly connected three phases Vienna rectifier with the electric grid via voltage transformer is shown in figure 4 (a), and further experiment results of $2.2 \mathrm{kw}$ rectifier are shown in figure 4 (b-g).

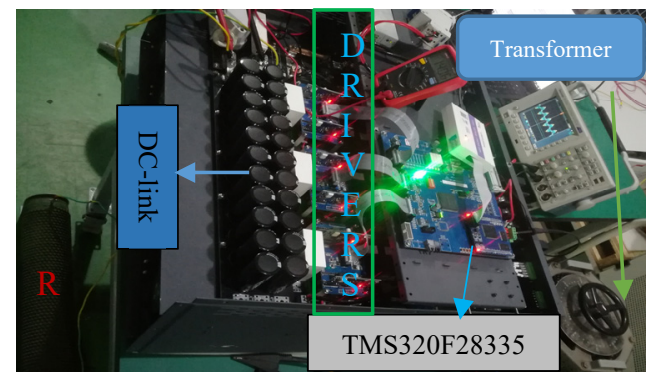

(a) 


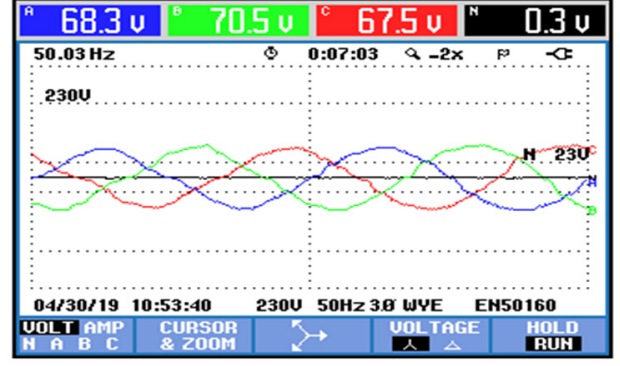

(b)

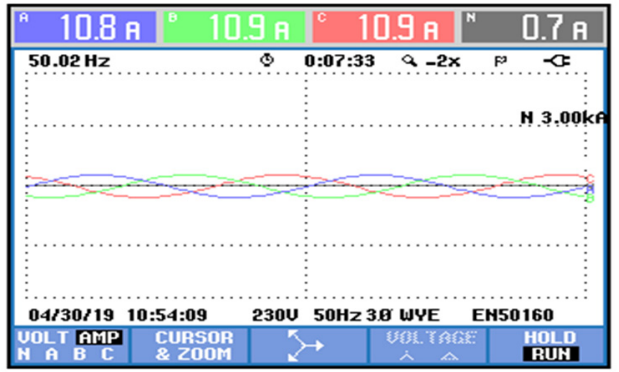

(c)

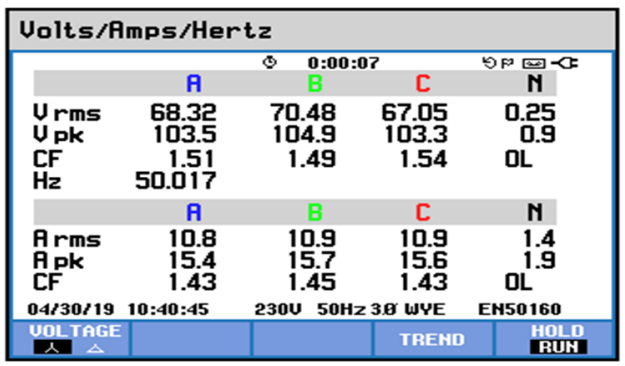

(d)

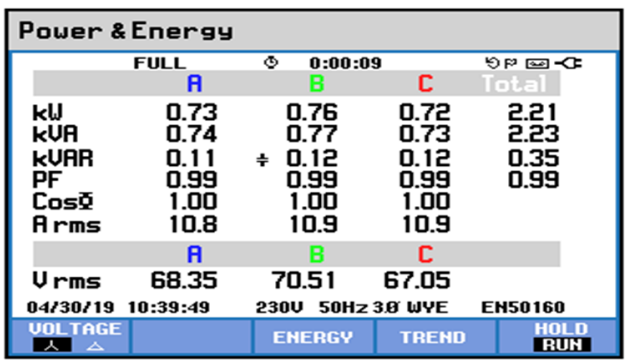

(e)

\begin{tabular}{|c|c|c|c|c|}
\hline \multicolumn{5}{|c|}{ HARMOMICS TABLE } \\
\hline Amp & ค & $\quad 0: 00: 08$ & & Эक 圈 \\
\hline THD\%f & 3.6 & 3.8 & 42 & 684 \\
\hline H3\% & 2.0 & 2.0 & 2.4 & 25.9 \\
\hline $45 \%$ & 1.0 & 1.5 & 1.6 & 16.0 \\
\hline $17 \%$ & & 0.5 & 0.5 & 12.1 \\
\hline H9\% & 0.8 & 0.7 & 1.1 & 8.8 \\
\hline H11\% & 3.0 & 1.6 & 0.9 & 6.0 \\
\hline $\begin{array}{l}\text { H13\%f } \\
\text { H15\% }\end{array}$ & $\begin{array}{l}2.0 \\
0.3\end{array}$ & 0.6 & 1.3 & 5.4 \\
\hline \multirow{2}{*}{\multicolumn{2}{|c|}{ 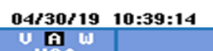 }} & \multicolumn{3}{|c|}{$230 \mathrm{U} 50 \mathrm{~Hz} 3.8$ WYE EN50160 } \\
\hline 8 & & $\begin{array}{l}\text { HAMMONI } \\
\text { GBAPH }\end{array}$ & TREAD & HOLD \\
\hline
\end{tabular}

(f)

Fig. 4. (a) Hardware setup, (b)Input voltages, (c) Input current waveforms, (d) Values of three phase input voltage and current, (e) Values of power and energy, (f) table of hormonic.

\section{Conclusion}

Comparative analysis of three-level active rectifiers based on their importance in WECS, utilization of the number of devices and their respective cost have been studied well. Among the discussed active rectifiers, a low-cost threelevel Vienna rectifier having high power density and simple control scheme has been implemented. Simulation and experimental results ratify that the control of Vienna rectifier also works well with good power factor and low harmonics at input current.

\section{Acknowledgement}

This work has been supported by the Shanghai Natural Science Foundation (SNSF) under grant 18ZR1418400.

\section{References}

1. Yaramasu, Venkata, Bin Wu, Paresh C. Sen, Samir Kouro, and Mehdi Narimani. "High-power wind energy conversion systems: State-of-the-art and emerging technologies." Proceedings of the IEEE 103, no. 5 (2015): 740-788.

2. Jain, Sarthak, and Lovely Goyal. "Current control methodology for PV in both standalone \& Gridconnected mode." 2014 IEEE 6th India International Conference on Power Electronics (IICPE). IEEE, 2014.

3. Vilathgamuwa, D. Mahinda, and SD Gamini Jayasinghe. "Rectifier systems for variable speed wind generation-a review." 2012 IEEE International Symposium on Industrial Electronics. IEEE, 2012.

4. "SKM 145GB123D product attributes”.Accessed:may.17,2019.[online]

Available:

https://www.findchips.com/search/IKW50N65H5.

5. “APT60DQ120BG product attributes". Accessed: may.17,2019.[online]

Available:https://www.digikey.com/products/en?ke ywords=APT60DQ120BG

6. Thandapani, T., R. Karpagam, and S. Paramasivam. "Comparative study of VIENNA rectifier topologies." International Journal of Power Electronics 7.3-4 (2015): 147-165.

7. "TLP250-product attributes".Accessed:May.17,2019.[online] Available: https:/www.bdent.com/tlp250-toshibaphotocoupler.html.

8. Kamal, Ahmad, and Abdul Basit. "High Power Medium Voltage PMSG based WECS using ThreeLevel Boost and Modular Multilevel Converters." 2018 International Conference on Power Generation Systems and Renewable Energy Technologies (PGSRET). IEEE, 2018.

9. Deng, Zhaozhe, et al. "Analysis and Control of Nlevel Neutral-point Clamped Dual Active Bridge DC-DC Converter with Capacitor Voltage 
Balance." 2018 International Conference on Power System Technology (POWERCON). IEEE, 2018.

10. Annoukoubi, Maha, Ahmed Essadki, Hammadi Laghridat, and Tamou Nasser. "Comparative study between the performances of a three-level and twolevel converter for a Wind Energy Conversion System." In 2019 International Conference on Wireless Technologies, Embedded and Intelligent Systems (WITS), pp. 1-6. IEEE, 2019.

11. "Vienna Rectifier-Based, Three-Phase Power Factor Correction (PFC) Reference Design Using C2000 MCU" TIDUCJ0D-November 2016-Revised May 2018
12. Mao, Meiqin, Chengyu Niu, and Liuchen Chang. "A novel simulator based on voltage source inverter for direct-drive PMSG wind generation system." 2013 IEEE ECCE Asia Downunder. IEEE, 2013.

13. Sejpal, Lekha. "Comparison of two-level and threelevel neutral-point clamped inverters in automotive applications." Ph.D. diss., Concordia University, 2013

14. M. Luqman, Y. gang, Z. Lidan, A. Lamichhane, "Analysis of variable speed wind energy conversion system for WECS" ICIEA conference (to be published) 